\title{
Identification of Human LRG1 Polymorphisms and Their Genetic Association with Rheumatoid Arthritis
}

\author{
Eun-Heui $\mathrm{Jin}^{1,4}$, Soo-Cheon Chae ${ }^{2 *}$, Seung- \\ Cheol Shim ${ }^{3}$, Hwan-Gyu Kim ${ }^{4}$ and Hun-Taeg \\ Chung ${ }^{1,5 *}$
}

${ }^{1}$ Genome Research Center for Immune Disorders, Wonkwang University School of Medicine, Iksan, Chonbuk 570-749, Korea, ${ }^{2}$ Department of Pathology, Wonkwang University School of Medicine, Iksan, Chonbuk 570-749, Korea, ${ }^{3}$ Division of Rheumatology, Department of Internal Medicine, Eulji University School of Medicine, Daejeon 301-831, Korea, ${ }^{4}$ Division of Biological Sciences, Research Center of Bioactive Materials, Chonbuk National University, Chunju, Chonbuk 561-756, Korea, ${ }^{5} \mathrm{Mi}-$ crobiology and Immunology, Wonkwang University School of Medicine, Iksan, Chonbuk 570-749, Korea

\begin{abstract}
Human leucine-rich alpha-2-glycoprotein 1 (LRG1) was first identified as a trace protein in human serum. The primary sequence of $\angle R G 1$ includes repeated leucine residues and putative membrane-binding domains. But, there is no published information on the genetic variation of this gene. In this study, LRG1 was identified as one of several upregulated genes in RA patients. We examined the expression levels of $\angle R G 1$ between an RA patient and a healthy control by RT-PCR and validated that $L R G 1$ was highly expressed in RA patients compared with controls. We identified the possible variation sites and single nucleotide polymorphisms (SNPs) in the human $L R G 1$ gene by direct sequencing and analyzed the association of genotype and allele frequencies between RA patients and a control group without RA. We further investigated the relationship between these polymorphisms and the level of RF or anti-CCP in RA patients. We identified a total of three SNPs (g.-678A > $\mathrm{G}, \mathrm{g} .-404 \mathrm{C}>\mathrm{T}$ and $\mathrm{g.1427T}>\mathrm{C}$ ) and two variation sites (g.-1198delA and g.-893delA) in the $L R G 1$ gene. Our results suggest that polymorphisms of the $L R G 1$ gene are not associated with the susceptibility of RA in the Korean population.
\end{abstract}

Keywords: HRM, LRG1, polymorphism, rheumatoid arthritis

*Corresponding author: E-mail chaesc@wonkwang.ac.kr htchung@wonkwang.ac.kr

Tel +82-63-850-6793, Fax +82-63-852-2110

Accepted 23 April 2008

\section{Introduction}

$\mathrm{RA}$ is a common systemic autoimmune disease that is characterized by chronic inflammation of the synovium, which can lead to progressive joint destruction, and is a complex disease that is a combination of multiple genetic factors and environmental contributions (Gregerin et al., 1999). RA is a disease that has a prevalence of $0.3 \%$ to $1 \%$ worldwide. RA is accompanied by the presence of many autoantibodies, such as rheumatoid factors (RFs), anti-cyclic citrullinated peptide (anti-CCP) antibody, and antibodies to immunoglobulin binding protein (BiP). RFs and anti-CCP antibody are used in clinical practice (Blass et al., 1999; Schellekens et al., 2000; Blass et al., 2001). RFs were the first described human autoantibodies and are directed to the Fc region of IgG and are usually of the IgM isotype (Waaler et al., 1940). They are detectable in up to $10 \%$ of normal individuals and $70 \%$ to $80 \%$ of patients with RA, and anti-CCP can be detected in up to $80 \%$ of patients with RA (Tighe et al., 2001). The RA susceptibility loci were identified, including 1p36, 5q31, and 21q22, by whole-genome linkage analysis (genome-wide association studies), and many polymorphisms also have been identified at these loci (Suzuki et al., 2003; Tokuhiro et al., 2003).

Human leucine-rich alpha-2-glycoprotein 1 (LRG1) was first identified as a trace protein in human serum (Haupt \& Baudner, 1977). The LRG1 gene is located on chromosome 19p13.3, and the primary sequence of LRG includes repeated leucine residues and also has putative membrane-binding domains. Serum $L R G 1$ is the first extracellular ligand for cytochrome $c$ (Cyt $c$ ). Cyt $c$ is a ubiquitous, heme-containing protein that normally resides in the space between the inner and outer mitochondrial membranes (Newmeyer et al., 2003). Extracellular Cyt $c$ may play a role in inflammation, as it has been reported to cause arthritis when it is injected into mice. Its levels in RA patients' sera are significantly lower than those of healthy controls (Pullerits et al., 2005). At least eight repeating 24-amino acid segments that have a notable consensus sequence were identified in a large family of LRG proteins. The function of LRG has not been elucidated, although the functions of many of the other members of the LRR (leucine-rich repeat)-containing superfamily are known (Kobe \& Deisenhofer, 1994; Buchanan \& Gay, 1996). Plasma LRG expression levels are lower in liver cancer patients who are treated with radiofrequency ablation (Kawakami 
et al., 2005). The expression levels of plasma LRG are high in idiopathic normal pressure hydrocephalus (INPH) and lung and pancreatic cancer patients (Kakisaka et al., 2007; Li et al., 2007; Okano et al., 2006). Li et al. reported that LRG is a specific biomarker in idiopathic normal pressure hydrocephalus (Li et al., 2006). Genetic studies of $L R G 1$ have not been reported.

We identified several candidate genes and proteins for RA patients by DNA microarray and 2-D gel analysis between RA patients and healthy controls (unpublished data). LRG1 was identified as one of several upregulated genes in RA patients. In this study, we identified the possible variation sites and single nucleotide polymorphisms (SNPs) in the human LRG1 gene by direct sequencing of genomic DNA that was isolated from 48 individuals (24 non-RA patients and 24 RA patients) and analyzed the association of genotype and allele frequencies between RA patients and a control group without RA. We further investigated the relationship between these polymorphisms and molecular markers (RF levels and anti-CCP) in RA patients.

\section{Methods}

\section{Subjects and DNA samples}

Blood samples and records were obtained from 520 RA patients (102 males, 418 females) and 567 controls (355 males, 212 females) without RA. The mean age of RA patients and controls was 53.2 years and 40.3 years, respectively. Genomic DNA was extracted from leukocytes in peripheral blood by a standard phenol-chloroform method or by using the Invisorb Spin Blood Maxi kit (Invitek, Germany) according to the manufacturer's instructions. Patients with RA were recruited from the outpatient clinic at Eulji University Hospital. RA was diagnosed according to criteria set forth by the American Rheumatism Association. CRP and RF levels in patients with RA were determined in a routine laboratory at Eulji University Hospital. The non-RA controls were recruited from the general population and had received comprehensive medical testing at Wonkwang University Hospital. All subjects in this study were Korean.

\section{Polymerase chain reaction (PCR) and DNA se- quencing}

PCR was performed using $50 \mathrm{ng}$ of genomic DNA, Taq DNA polymerase (EF Taq, SolGent, Korea), and $0.5 \mu \mathrm{M}$ of each primer (Table 1) under the following conditions: 30 cycles of PCR consisting of denaturation for $10 \mathrm{sec}$ at $98^{\circ} \mathrm{C}$, annealing for $30 \mathrm{sec}$ at $65^{\circ} \mathrm{C}$, extension for 1 min at $72^{\circ} \mathrm{C}$, and a final extension for $10 \mathrm{~min}$ at $72^{\circ} \mathrm{C}$ in a thermocycler (Gene Amp PCR system 9700, PE Applied Biosystems, USA). After purification using a PCR purification kit (Millipore, Ireland), the PCR products were used as template DNA for sequencing analysis (ABI Prism BigDye Terminator cycle sequencing system; ABI 3100 automatic sequencer, PE Applied Biosystems, USA). For sequencing, the same PCR pri-

Table 1. Primer sequences used for amplification, sequence analysis, and genotyping of the $L R G 1$ gene

\begin{tabular}{|c|c|c|c|}
\hline Application & Primer name & Primer sequence $\left(5^{\prime} \rightarrow 3^{\prime}\right)$ & Region \\
\hline \multirow[t]{6}{*}{ PCR analysis } & LRG1-PF1 & ACCCGCCACCACGCCCCGCT & Promoter \\
\hline & LRG1-PR1 & TCCCCACCCCCGTCCAGTTCCTGA & \\
\hline & LRG1-PF2 & AGCCAAGTCCATGAGATGCAGCCA & Promoter and Exon1 \\
\hline & LRG1-PR2 & AGCAAATCCGCCCACTTCTTCCCA & \\
\hline & LRG1-PF3 & ACACACACCCCTACAGAAGCCCA & Exon2 \\
\hline & LRG1-PR3 & ACCATATCCCACACCCCAGGGCCT & \\
\hline \multirow[t]{7}{*}{ DNA sequencing analysis } & LRG1-SF1 & CCAGGAGTTTGAGACCAGCCT & Promoter \\
\hline & LRG1-SR1 & TCAGTTTCCCCATCTATGAAGCTGA & Promoter \\
\hline & LRG1-SF2 & GCATGGTGGCTCACACCTGT & Promoter \\
\hline & LRG1-SF3 & ACAGGTGAGAGATGAGGTAGCAT & Exon2 \\
\hline & LRG1-SF4 & ACCTGCCAGCCAACCTCCT & Exon2 \\
\hline & LRG1-SF5 & TCCTGAGGGGTCCGCTGCA & Exon2 \\
\hline & LRG1-SF6 & TGGTAGAACACTGCAACCCGCT & Exon2 \\
\hline \multirow[t]{2}{*}{ RT-PCR } & LRG1-RF1 & ACCAGGGGCTTGGGTTGAGGGT & 3'- UTR \\
\hline & LRG1-RR1 & TCTGGGAAACAGGGAACGGCA & \\
\hline \multirow[t]{6}{*}{ HRM analysis } & LRG1-HF1 & TGGAAACAATAGCATGGATGTCA & g. $-678 \mathrm{~A}>\mathrm{G}$ \\
\hline & LRG1-HR1 & CTTTGTGACCTTTGGCAAGTGAC & \\
\hline & LRG1-HF2 & CAACATACCATGAAATCAAGACGAGT & g. $-404 \mathrm{~T}>\mathrm{C}$ \\
\hline & LRG1-HR2 & TGCAAGGCACTATTCCTGGAGA & \\
\hline & LRG1-HF3 & GCTGGAAAGCCTCTCGCCCGA & g. $1427 \mathrm{C}>\mathrm{T}$ \\
\hline & LRG1-HR3 & TCAATACCAGGGTGTCCAGGGT & \\
\hline
\end{tabular}


mers and four additional primers were used (Table 1). The reference sequence of $L R G 1$ was based on human chromosome 19 clone CTB-50L17.

\section{RNA extraction and RT-PCR}

For total RNA, human peripheral blood mononuclear cells (PBMC) from four pairs of RA patients and healthy controls were isolated from the buffy coats by density gradient centrifugation using Ficoll-Paque Plus (Amersham Biosciences, Sweden), washed with phosphatebuffered saline (GIBCO BRL, Invitrogen, USA), and lysed in TRIzol reagent (Invitrogen, USA) according to the instructions of the manufacturer. Approximately 1-2 $\mu \mathrm{g}$ of total RNA was used in the first-strand cDNA synthesis with a sequence-specific primer using M-MLV reverse transcriptase (Bioneer, Korea) for RT-PCR. The expression assay for several tissues was performed using multiple human tissue cDNAs (Clontech, USA).

\section{Genotype analysis}

Genotyping was performed by high resolution melting (HRM) analysis. The intercalating dye that was used was EvaGreen (Biotium, USA). The $10-\mu \mathrm{L}$ reaction mixture was made up using the $1 \times$ QuantiTect Probe PCR Kit (Qiagen, USA) and consisted of $50 \mathrm{ng}$ of genomic DNA, $100 \mathrm{nM}$ of each primer, and $1 \times$ Evagreen solution. PCR cycling and HRM analysis was carried out using the Rotor-Gene thermal cycler RG6000 (Corbett Research, Australia). The 138-bp, 127-bp, and 133-bp amplicons were produced according to the following conditions; one cycle at $95^{\circ} \mathrm{C}$ for $15 \mathrm{~min} ; 45$ cycles at $95^{\circ} \mathrm{C}$ for 15 sec, $68^{\circ} \mathrm{C}$ for $10 \mathrm{sec}$, and $72^{\circ} \mathrm{C}$ for $30 \mathrm{sec}$. Optical measurements in the green channel (excitation at 470 $\mathrm{nm}$ and detection at $519 \mathrm{~nm}$ ) were recorded during the extension step. After a completion of 45 cycles, melting curve data were generated by increasing the temper- ature from $77^{\circ} \mathrm{C}$ to $95^{\circ} \mathrm{C}$ at $0.1^{\circ} \mathrm{C}$ per second and recording fluorescence. HRM curve analysis was performed using the software Rotor-Gene 1.7.40 and the HRM algorithm that was provided.

\section{Statistical analysis}

The RA patients and controls without RA were compared by case-control association analyses. $\chi^{2}$ tests were used to estimate the Hardy-Weinberg equilibrium (HWE). Pair-wise comparison of biallelic loci was employed for the analyses of linkage disequilibrium (LD). The haplotype frequencies of $L R G 1$ for multiple loci were estimated using the expectation maximization (EM) algorithm with SNPAlyze software (DYNACOM, Japan). ANOVA was applied to analyze differences between the genotype and anti-CCP or RF levels in RA patients. A $P$ value of less than 0.05 was considered to indicate statistical significance.

\section{Results}

We have studied cDNA microarrays with mRNAs from four RA patients and four controls and 2-DE analysis to examine the expression level of mRNAs as well as the difference in protein levels between RA patients and controls (unpublished data). Human leucine-rich alpha-2-glycoprotein 1 ( $L R G 1$ ) was identified as one of many upregulated genes in RA patients in both the cDNA microarray and 2-D gel analysis. We confirmed the expression levels of $L R G 1$ between RA patients and healthy controls by RT-PCR and validated that $L R G 1$ was highly expressed in RA patients compared with controls (Fig. 1A). We also examined the expression pattern of $L R G 1$ in 15 normal human tissues and peripheral leukocytes. Our results showed that the expression level of $L R G 1$ mRNA was highest in peripheral leukocytes, while the expression level of $L R G 1 \mathrm{mRNA}$ in
A

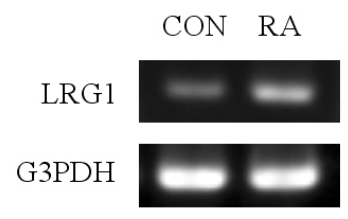

B
Fig. 1. Expression levels and patterns of $L R G 1 \mathrm{mRNA}$ by three independent tests. (A) The expression levels of LRG1 mRNA between RA patients and healthy controls, (B) the expression patterns of $L R G 1$ mRNA in various human tissues. Lanes: 1, heart; 2, brain; 3, placenta, 4, lung; 5, liver; 6, skeletal muscle; 7, kidney; 8, pancreas; 9, spleen; 10, thymus; 11 , prostate; 12 , testis; 13 , ovary; 14 , small intestine; 15 , colon; and 16 , peripheral leukocytes. 
brain and skeletal muscle was only barely detected (Fig. 1B).

To determined the possible variation sites in entire sequences of the $L R G 1$ gene. including about $2.0 \mathrm{~kb}$ of the promoter region, we first scanned the genomic DNA that was isolated from 24 unrelated controls and 24 RA patients by a direct sequencing method. We identified three SNPs-g.-678A $>$ G (novel SNP) and g.-404T $>C$ (rs4806985) in the promoter region, g.1427T $>C$ (rs966384) in exon2-and two novel variation sites (g.-1198 delA and g.-893 delA) (Fig. 2). Linkage disequilibrium (LD) coefficients (ID'l) were calculated between all SNP pairs. Although an absolute LD (ID'|=1 and $r^{2}=1$ ) was not found, strong LDs were found between $g .-404 C>T$ and g. 1427C $>T$, and between g. $-678 A>G$ and $g$. 1427T $>$ $C\left(\left|D^{\prime}\right|=0.91\right.$ and 0.90 , respectively). A single nucleotide transition ( $\mathrm{T}$ to $\mathrm{C}$ ) at $\mathrm{g} .1427 \mathrm{~T}>\mathrm{C}$ resulted in an amino acid change to p.Pro133Ser. We analyzed the genotype of these SNPs in RA patients and in controls by the HRM method and compared the genotype frequencies between these groups. The genotype frequencies of all loci were in HWE ( $p>0.05$, data not shown). The genotype and allele frequencies of g. $-678 \mathrm{~A}>\mathrm{G}, \mathrm{g} .-404 \mathrm{C}>\mathrm{T}$, and $g .1427 \mathrm{~T}>\mathrm{C}$ were not significantly different between RA patients and controls. These results suggest that the SNPs of LRG1 are not associated with susceptibility to RA (Table 2).

On the other hand, to define a possible correlation between polymorphisms and clinical features of RA, we further analyzed each genotype of these SNPs with anti-CCP and RF levels in RA patients (Table 3). We found that these SNPs in RA patients have no significant as-

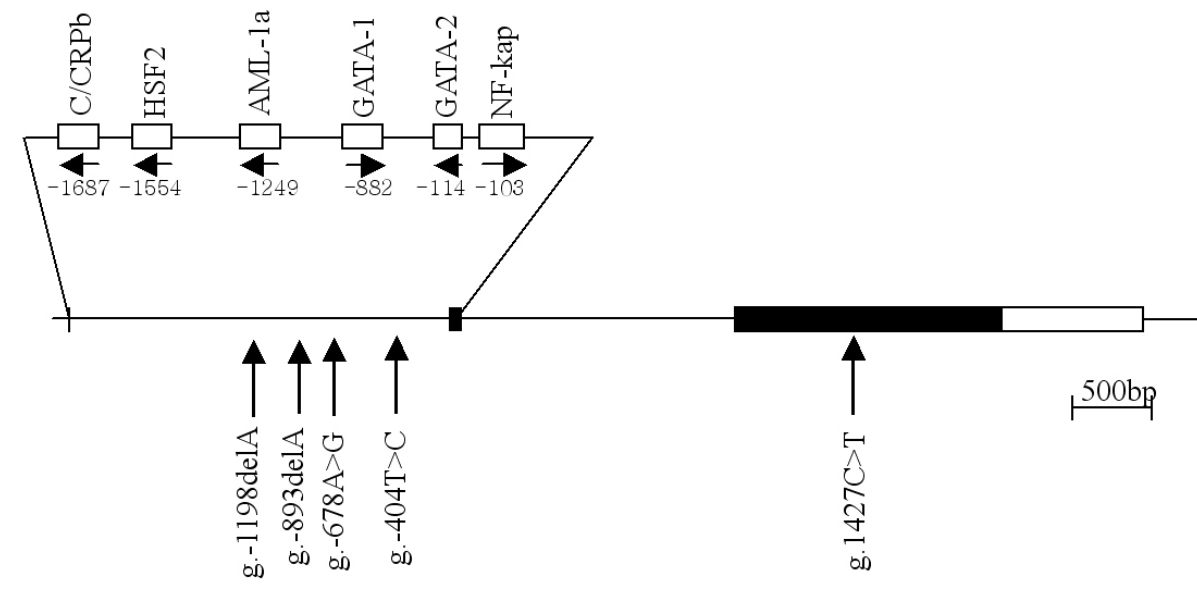

Fig. 2. Location of each single nucleotide polymorphism (SNP) and sites of variation in LRG1. Coding exons are marked by filled blocks and 3'-untranslated regions (UTR) by open block. The positions of SNPs were calculated from the translation start site. Putative transcription factor sites at http://www.cbrc.jp/research/db/ TFSERCH.html. The reference sequence for LRG1 was based on the sequence of human chromosome 19 clone CTB-50L17.

Table 2. Genotype and allele frequencies in the SNPs of $L R G 1$ between RA patients and controls

\begin{tabular}{|c|c|c|c|c|}
\hline Position* & Genotype/Allele & Control, n (\%) & $\mathrm{RA}, \mathrm{n}(\%)$ & $p$ value $^{\dagger}$ \\
\hline \multirow[t]{5}{*}{ g. $-678 \quad A>G$} & AA & $422(75.8)$ & $394(75.3)$ & 0.985 \\
\hline & $A G$ & $131(23.5)$ & $125(23.9)$ & \\
\hline & GG & $4(0.7)$ & $4(0.8)$ & \\
\hline & A & $975(87.5)$ & $913(87.3)$ & 0.897 \\
\hline & $\mathrm{G}$ & $139(12.5)$ & $133(12.7)$ & \\
\hline \multirow[t]{5}{*}{ g. $-404 \quad$ C $>$ T (rs4806985) } & $\mathrm{CC}$ & $225(40.1)$ & $216(41.6)$ & 0.701 \\
\hline & CT & $261(46.5)$ & $243(46.7)$ & \\
\hline & $\mathrm{TT}$ & $75(13.4)$ & $61(11.7)$ & \\
\hline & C & $711(63.4)$ & $675(64.9)$ & 0.473 \\
\hline & $\mathrm{T}$ & $411(36.6)$ & $365(35.1)$ & \\
\hline \multirow[t]{5}{*}{ g.1427 T>C (rs966384) } & TT & $138(24.7)$ & $141(27.0)$ & 0.677 \\
\hline & TC & $295(52.8)$ & $272(52.0)$ & \\
\hline & $\mathrm{CC}$ & $126(22.5)$ & $111(21.0)$ & \\
\hline & $\mathrm{T}$ & $571(51.1)$ & $554(53.0)$ & 0.414 \\
\hline & C & 547 (48.9) & $494(47.0)$ & \\
\hline
\end{tabular}

${ }^{*}$ Calculated from the translation start site.

${ }^{\dagger}$ Value was determined by $\chi^{2}$ test from $2 \times 3$ contingency table. 
Table 3. The levels of rheumatoid factors (RF) and anti-CCP among the genotypes of polymorphisms of the $L R G 1$ gene in RA

\begin{tabular}{|c|c|c|c|c|c|c|c|c|c|}
\hline \multirow{2}{*}{ Position* } & \multirow{2}{*}{ Genotype } & \multicolumn{3}{|c|}{$\mathrm{RF}$} & \multirow{2}{*}{$\mathrm{p}^{\dagger}$} & \multicolumn{3}{|c|}{ anti-CCP } & \multirow{2}{*}{$\mathrm{p}^{\dagger}$} \\
\hline & & $\mathrm{n}$ & Mean & SD & & $\mathrm{n}$ & Mean & SD & \\
\hline \multirow[t]{3}{*}{ g. $-678 \quad A>G$} & AA & 328 & 73.7 & 77.1 & \multirow[t]{3}{*}{0.18} & 176 & 53.6 & 51.0 & \multirow[t]{3}{*}{0.57} \\
\hline & $A G$ & 116 & 62.8 & 68.3 & & 71 & 57.7 & 51.7 & \\
\hline & GG & 1 & - & - & & 1 & - & - & \\
\hline \multirow{3}{*}{$\begin{array}{r}\text { g. }-404 \text { C > T } \\
(\text { rs4806985) }\end{array}$} & $\mathrm{CC}$ & 189 & 70.6 & 73.3 & \multirow[t]{3}{*}{0.66} & 111 & 52.6 & 51.7 & \multirow[t]{3}{*}{0.81} \\
\hline & CT & 206 & 69.8 & 76.2 & & 114 & 56.1 & 50.0 & \\
\hline & TT & 55 & 80.0 & 80.1 & & 25 & 58.8 & 58.0 & \\
\hline \multirow{3}{*}{$\begin{array}{c}\mathrm{g} .1427 \mathrm{~T}>\mathrm{C} \\
(\mathrm{rs} 966384)\end{array}$} & $\mathrm{TT}$ & 118 & 76.5 & 76.4 & \multirow[t]{3}{*}{0.65} & 66 & 50.3 & 52.0 & \multirow[t]{3}{*}{0.77} \\
\hline & TC & 227 & 68.5 & 75.1 & & 131 & 56.0 & 50.1 & \\
\hline & $\mathrm{CC}$ & 102 & 70.7 & 76.1 & & 51 & 54.7 & 53.4 & \\
\hline
\end{tabular}

${ }^{*}$ Calculated from the translation start site.

${ }^{\dagger}$ Values were analyzed by ANOVA.

sociation with the levels of RF and anti-CCP (Table 3). We also calculated and compared the haplotype frequencies among the g. $-678 \mathrm{~A}>\mathrm{G}$, g. $-404 \mathrm{C}>\mathrm{T}$, and g.1427T $>$ C SNPs of $L R G 1$ between controls and RA patients. Three major haplotypes out of eight possible haplotypes were identified that revealed more than $93.3 \%$ and $97.8 \%$ distribution in the controls and RA patients, respectively (Table 4). The distribution rate of the haplotype $A C C$ was significantly different between the controls and RA patients $(p<0.0003)$.

\section{Discussion}

$\mathrm{RA}$ is a chronic, systemic inflammatory disorder that affects approximately $1 \%$ of the population, at a female-to-male ratio of 3:1 (Schena et al., 1995). In this study, the genotype and allele frequencies of $L R G 1$ SNPs were not significantly different between RA patients and controls (Table 2). This result indicates that the LRG1 SNPs are not associated with a susceptibility to RA.

LRG has putative membrane-binding domains, which is suggestive of the possibility of protein-protein and protein-deoxyribonucleic acid interaction (Takahashi et al., 1985; Kobe \& Deisenhofer, 1994). LRG1 is a novel ligand for Cyt $c$. The observation of Cyt $c$ in normal serum and its binding to $L R G 1$ suggests that these two molecules may have physiological relevance. Cyt $C$ could serve as an adaptor by altering the activity of LRG1. Pullerits et al. reported that Cyt $c$ levels in the synovial fluid of RA patients were low (Pullerits et al., 2005). Several studies have reported that serum LRG expression levels were high in INPH and cancers. In the present study, the expression levels of plasma $L R G 1$ mRNA were higher in RA patients than in healthy controls. Our result also showed that the expression lev-
Table 4. The haplotype frequencies in both RA patients and controls of $L R G 1$ polymorphisms

\begin{tabular}{|c|c|c|c|c|c|}
\hline \multicolumn{3}{|c|}{ Haplotype } & \multicolumn{2}{|c|}{ Frequency ${ }^{*}$} & \multirow{2}{*}{$p^{\dagger}$} \\
\hline $\begin{array}{l}\text { g. }-678 \\
A>G\end{array}$ & $\begin{array}{c}\text { g. }-404 \\
C>T\end{array}$ & $\begin{array}{c}\text { g. } 1427 \\
T>C\end{array}$ & Control & $\mathrm{RA}$ & \\
\hline A & C & T & 0.492 & 0.518 & 0.238 \\
\hline A & $\mathrm{T}$ & C & 0.333 & 0.342 & 0.663 \\
\hline G & C & C & 0.108 & 0.118 & 0.478 \\
\hline A & C & C & 0.037 & 0.012 & $<0.0003$ \\
\hline A & $\mathrm{T}$ & $\mathrm{T}$ & 0.01 & $5.1 \mathrm{E}-3$ & 0.176 \\
\hline G & $\mathrm{T}$ & C & $9.4 \mathrm{E}-3$ & $9.5 \mathrm{E}-4$ & 0.0075 \\
\hline G & C & $\mathrm{T}$ & $7.3 \mathrm{E}-3$ & $2.9 \mathrm{E}-3$ & 0.154 \\
\hline G & $\mathrm{T}$ & T & $3.8 \mathrm{E}-3$ & $2.0 \mathrm{E}-3$ & 0.44 \\
\hline
\end{tabular}

*Values were constructed by the expectation maximization (EM) algorithm with genotyped SNPs.

${ }^{\dagger}$ Values were analyzed by the permutation test.

el of $L R G 1$ mRNA was the highest in peripheral leukocytes compared with various human tissues (Fig. 1B). Our novel approach might suggest that $L R G 1$ may be related to inflammatory responses in peripheral blood.

cDNA microarray technology allows for expression monitoring, identification, and quantification of thousands of genes simultaneously (Schena et al., 1995; Shalon et al., 1996). Using the cDNA microarray method, expression analysis in diseased RA tissue was conducted and demonstrated its utility to analyze complex diseases, such as RA, systemic lupus erythematosus (SLE), and inflammatory bowel disease (Heller et al., 1997). Recently, gene expression profiles have been identified from peripheral blood cells of patients with SLE, RA, and multiple sclerosis (MS) (Baechler et al., 2003; Batliwalla et al., 2005; Bomprezzi et al., 2003). We previously performed cDNA microarray and 2-D gel 
analysis to screen RA-related specific genes. About 144 and 62 genes were identified as having more than 5.0-fold higher or lower mRNA levels in RA patients (unpublished data). Even though the expression levels of $\angle R G 1$ were higher in RA patients than in controls, the genetic polymorphisms of LRG1 might not be associated with the susceptibility of this immune disorder.

A hallmark of RA is the presence of autoantibodies; therefore, we evaluated whether these SNPs have associations with RF and anti-CCP. But the genotypes of $\angle R G 1$ gene polymorphisms have no significant association with the RF and anti-CCP levels in RA patients (Table 3). These results suggest that the polymorphisms of $L R G 1$ are not associated with these factors in RA patients.

In conclusion, the g. $-678 \mathrm{~A}>\mathrm{G}, \mathrm{g} .-404 \mathrm{C}>\mathrm{T}$, and g.1427T $>C$ polymorphisms of the $L R G 1$ gene do not confer genetic susceptibility to RA in Koreans.

\section{Acknowledgements}

This work was supported by a grant from the Korea Health 21 R\&D Project and by the Ministry of Health \& Welfare (A010251).

\section{References}

Baechler, E.C., Batliwalla, F.M., Karypis, G., Gaffney, P.M., Ortmann, W.A., Espe, K.J., Shark, K.B., Grande, W.J., Hughes, K.M., Kapur, V., Gregersen, P.K., and Behrens, T.W. (2003). Interferon-inducible gene expression signature in peripheral blood cells of patients with severe lupus. Proc. Natl. Acad. Sci. USA. 100, 2610-2615.

Batliwalla, F.M., Baechler, E.C., Xiao, X., Li, W.,

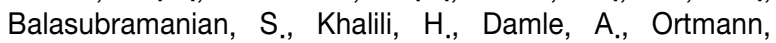
W.A., Perrone, A., Kantor, A.B., Gulko, P.S., Kern, M., Furie, R., Behrens, T.W., and Gregersen, P.K. (2005). Peripheral blood gene expression profiling in rheumatoid arthritis. Genes. Immunol. 6, 388-397.

Blass, S., Engel, J.M., and Burmester, G.R. (1999). The immunologic homunculus in rheumatoid arthritis. Arthritis Rheum. 42, 2499-2506.

Blass, S., Union, A., Raymackers, J., Schumann, F., Ungethum, U., Muller-Steinbach, $S$., De Keyser, F., Engel, J.M., and Burmester, G.R. (2001). The stress protein $\mathrm{BiP}$ is overexpressed and is a major $\mathrm{B}$ and $\mathrm{T}$ cell target in rheumatoid arthritis. Arthritis Rheum. 44, 761-771.

Bomprezzi, R., Ringner, M., Kim, S., Bittner, M.L., Khan, J., Chen, Y., Elkahloun, A., Yu, A., Bielekova, B., Meltzer, P.S., Martin, R., McFarland, H.F., and Trent, J.M. (2003). Gene expression profile in multiple sclerosis patients and healthy controls: identifying pathways relevant to disease. Hum. Mol. Genet. 12, 2191-2199.

Buchanan, S.G., and Gay, N.J. (1996). Structural and functional diversity in the leucine-rich repeat family of proteins. Prog. Bioohys. Mol. Biol. 65, 1-44.

Gregerin, P.K. (1999). Genetics of rheumatoid arthritis : confronting complexity. Arthritis Res, 1, 37-44.

Haupt, H., and Baudner, S. (1977). Isolation and characterization of an unknown, leucine-rich 3.1-S-alpha2-glycoprotein from human serum. Hoppe Seylers Z. Phisiol. Chem. (article in German). 358, 639-646.

Heller, R.A., Schena, M., Chai, A., Shalon, D., Bedilion, T., Gilmore, J., Woolley, D.E., and Davis, R.W. (1997). Discovery and analysis of inflammatory disease-related genes using cDNA microarrays. Proc. Natl. Acad. Sci. USA, 94, 2150-2155.

Kakisaka, T., Kondo, T., Okano, T., Fujii, K., Honda, K., Endo, M., Tsuchida, A., Aoki, T., Itoi, T., Moriyasu, F., Yamada, T., Kato, H., Nishimura, T., Todo, S., and Hirohashi, S. (2007). Plasma proteomics of pancreatic cancer patients by multi-dimensional liquid chromatography and two-dimensional difference gel electrophoresis (2D-DIGE) : Up-regulation of leucine-rich alpha-2-glycoprotein in pancreatic cancer. J. Chroma. B. 852, 257-267.

Kawakami, T., Hoshida, Y., Kanai, F., Tanaka, Y., Tateishi, K., Ikenoue, T., Obi, S., Sato, S., Teratani, T., Shiina, S., Kawabe, T., Suzuki, T., Hatano, N., Taniguchi, H., and Omata, M. (2005). Proteomic analysis of sera from hepatocellular carcinoma patients after radiofrequency ablation treatment. Proteomics 5, 4287-4295.

Kobe, B., and Deisenhofer, J. (1994). The leucine-rich repeat : a versatile binding motif. TIBS. 19, 415-421.

Li, X., Miyajima, M., Jiang, C., and Arai, H. (2007). Expression of TGF- $\beta \mathrm{s}$ and TGF- $\beta$ type II receptor in cerebrospinal fluid of patients with idiopathic normal pressure hydrocephalus. Neuro. Letters 413, 141-144.

Li, X., Miyajima, M., Mineki, R., Taka, H., Murayama, K., and Arai, H. (2006). Analysis of potential diagnostic biomarkers in cerebrospinal fluid of idiopathic normal pressure hydrocephalus by proteomics. Acta. Neurochir. (Wien) 148, 859-864.

Newmeyer, D.D., and Ferguson-Miller, S. (2003). Mitochondria: releasing power for life and unleashing the machineries of death. Cell 112, 481-490.

Okano, T., Kondo, T., Kakisaka, T., Fujii, K., Yamada, M.,

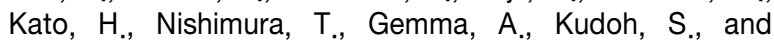
Hirohashi, S. (2006). Plasma proteomics of lung cancer by a linkage of mlti-dimensional liquid chromatography and two-dimensional difference gel electrophoresis. Proteomics, 6, 3938-3948.

Pullerits, R., Bokarewa, M., Jonsson, I.M., Verdrengh, M., and Tarkowski, A. (2005). Extracellular cytochrome c, a mitochondrial apoptosis-related protein, induces arthritis. Rheumatology 44, 32-39.

Schellekens, G.A., Visser, $H_{\text {., }}$ de Jong, B.A., van den Hoogen, F.H., Hazes, J.M., Breedveld, F.C., and van Venrooij, W.J. (2000). The diagnostic properties of rheumatoid arthritis antibodies recognizing a cyclic citrullinated peptide. Arthritis Rheum. 43, 155-163.

Schena, M., Shalon, D., Davis, R.W., and Brown, P.O. (1995). Quantitative monitoring of gene expression patterns with a complementary DNA microarray. Science 270, 467-470. 
Shalon, D., Smith, S., and Brown, P.O. (1996). A DNA microarray system for analyzing complex DNA samples using two-color fluorescent probe hybridization. Genome Res. 6, 639-645.

Shukaili, A., and Jabri, A. (2006). Rheumatoid arthritis, cytokines and hypoxia. What is the link? Saudi Med. J. 27, 1642-1649.

Suzuki, A., Yamada, R., Chang, X., Tokuhiro, S., Sawada, T., Suzuki, M., Nagasaki, M., Nakayama-Hamada, M., Kawaida, R., Ono, M., Ohtsuki, M., Furukawa, H., Yoshino, S., Yukioka, M., Tohma, S., Matsubara, T., Wakitani, S., Teshima, R., Nishioka, Y., Sekine, A., lida, A., Takahashi, A., Tsunoda, T., Nakamura, $Y_{.}$, and Yamamoto, K. (2003). Functional haplotypes of PADI4, encoding citrullinating enzyme peptidylarginine deiminase 4 , are associated with rheumatoid arthritis. Nat. Genet. 34, 395-402.

Takahashi, N., Takahashi, Y., and Putnam, F.W. (1985). Periodicity of leucine and tandem repetition of a 24-ami- no acid segment in the primary structure of leucine-rich $\alpha_{2}$-glycoprotein of human serum. Proc. Natl. Acad. Sci. USA 82, 1906-1910.

Tighe, $\mathrm{H}_{\text {., }}$ and Carson, D.A. (2001). Rheumatoid factor. In Kelley's Textbook of Rheumatology, Ruddy, S., Harris, E. D., Sledge, C., eds. (Philadelphia: W.B. Saunders Company), pp.151-161

Tokuhiro, S., Yamada, R., Chang, X., Suzuki, A., Kochi, Y., Sawada, T., Suzuki, M., Nagasaki, M., Ohtsuki, M., Ono, M., Furukawa, H., Nagashima, M., Yoshino, S., Mabuchi, A., Sekine, A., Saito, S., Takahashi, A., Tsunoda, T., Nakamura, Y., and Yamamoto, K. (2003). An intronic SNP in a RUNX1 binding site of SLC22A4, encoding an organic cation transporter, is associated with rheumatoid arthritis. Nat. Genet. 35, 341-348.

Waaler, E. (1940). On the occurrence of a factor in human serum activating the specific agglutination of sheep blood corpuscles. Acta. Pathol. Microbiol. Scand. 17, 172. 